\title{
Role of cyclic AMP in the modulation of IgE production by the $\beta_{2}$-adrenoceptor agonist, fenoterol
}

\author{
O. Coqueret*+, D. Demarquay*, V. Lagente**
}

Role of cyclic AMP in the modulation of IgE production by the $\beta_{2}$-adrenoceptor agonist, fenoterol. O. Coqueret, D. Demarquay, V. Lagente. CERS Journals Ltd 1996.

ABSTRACT: We have previously demonstrated that the $\beta_{2}$-adrenoceptor agonist, salbutamol, potentiates the effect of interleukin-4 (IL-4) on immunoglobulin E (IgE) production by human peripheral blood mononuclear cells (PBMC).

This study was undertaken to further define the activities of these drugs and the role of cyclic-adenosine monophosphate (cAMP) in the modulation of IgE production.

Our results indicate that fenoterol $(1 \mu \mathrm{M})$ potentiated IL-4-induced IgE production and IgE messenger ribonucleic acid (mRNA) expression. Moreover, this effect was associated with an increase in intracellular cAMP levels. The activities of this drug on IgE production were mimicked by cell permeable cAMP analogues, such as dibutyryl-cAMP (db-cAMP) $(100 \mu \mathrm{M})$ or Sp-AMP $(10 \mu \mathrm{M})$. The potentiating effect of fenoterol on IgE production was markedly inhibited in the presence of protein kinase A (PKA) inhibitors: H8 $(10 \mu M)$ and Rp-AMP $(10 \mu M)$, suggesting that its effects are likely to depend on the activation of the cAMP pathway. Additionally, the potentiating effect of fenoterol was also blocked in the presence of indomethacin. Fenoterol potentiated IL-4-induced IgE production from purified B-cells activated through their CD40 antigen. This effect was associated with an increase in cellular viability. Therefore, the activities of this drug on PBMC are likely to be mediated by the activation of another cellular type.

Taken together, these results show that fenoterol potentiates the IL-4-induced IgE production via the cAMP pathway, but that this enhancement could not be explained by a direct effect on B-lymphocytes.

Eur Respir J., 1996, 9, 220-225.

\begin{abstract}
*Département d'Immunologie, Institut Henri Beaufour, Les Ulis, France. ** Laboratoire de Pharmacodynamie, Faculté des Sciences Pharmaceutiques et Biologiques, Université de Rennes, Rennes, France. +Present address: Molecular Oncology group, Royal Victoria Hospital, McGill University, Montreal, Quebec, Canada.
\end{abstract}

Correspondence: V. Lagente Laboratoire de Pharmacodynamie Faculté des Sciences Pharmaceutiques et Biologiques

Université de Rennes 1

2, avenue du Prof. Léon Bernard

35043 Rennes cedex

France

Keywords: $\beta_{2}$-adrenergic

CD40

cyclic adenosine monophosphate

fenoterol

immunoglobulin $\mathrm{E}$

Received: April 101995

Accepted after revision October 121995
Inhaled $\beta_{2}$-adrenoceptor agonists are the most effective of the available bronchodilator drugs used to treat asthma. They induce bronchial smooth muscle relaxation and are potent inhibitors of mediator release by mast cells $[1,2]$. However, despite this beneficial effect, recent studies have suggested that the regular use of $\beta_{2}$ adrenoceptor agonists in asthma has, controversially, been claimed to lead to a further progression of the disease $[3,4]$, and may be associated with increased morbidity and even mortality [5]. Indirect evidence also suggests that $\beta_{2}$-adrenergic agonists play a role in the modulation of immunity. For example, $\beta_{2}$-adrenergic stimulation of lymphocytes produces changes in such parameters as Tcell proliferation [6], antibody synthesis [7] and eicosanoid production [8]. Following the activation of the $\beta_{2}$-adrenoceptor, these drugs induce an enhancement of adenosine 3',5'-cyclic-monophosphate (cyclic-AMP, cAMP) levels [9]. This increase is followed by the activation of cytoplasmic cAMP-dependent protein kinase A (PKA), the translocation of the kinase to the nucleus and ultimately the phosphorylation of nuclear transcription factors, such as the cAMP response element-binding protein (CREB) [10]. Thus, cAMP plays a key role in the regulation of lymphocyte activation, but its effect depends on the cell type, signals and stages of cell-cycle activation.
Despite the clinical importance of immunoglobulin E (IgE) in allergic reactions, little attention has been paid to the effect of $\beta_{2}$-adrenoceptor agonists on the regulation of the production of this antibody. We have previously demonstrated that salbutamol potentiates the effect of interleukin-4 (IL-4) on IgE production from human peripheral blood mononuclear cells (PBMC), which might be explained by an inhibition of interferon- $\gamma$ (IFN- $\gamma$ ) production [11]. The same effect was observed in vitro and in vivo in the mouse, where it could be associated with an increased release of Th2-type lymphokines from murine splenocytes [12]. The present study was undertaken to further characterize the effect of the $\beta_{2}$-adrenoceptor agonist, fenoterol, on human IgE production. In addition, the role of the intracellular cAMP level and PKA activation was analysed.

\section{Methods}

\section{Reagents}

The following reagents were obtained as noted. Recombinant human interleukin-4 (IL-4, $1 \times 10^{7} \mathrm{U} \cdot \mathrm{mg}^{-1}$ ) was purchased from Biotrans (Los Angeles, CA, USA). Foetal calf serum (FCS), phosphate-buffered saline (PBS), 
glutamine, penicillin and RPMI 1640 were from Flow (Irvine, Scotland). Fenoterol, N6, 2 -O-dibutyryladenosine 3':5'-cyclic monophosphate (db-cAMP), indomethacin, $\mathrm{N}-5$-isoquinolinesulphonamide (H8), ortho-phenylenediamine (OPD), bovine serum albumin (BSA) and saline sodium phosphate ethylenediamine tetra-acetic acid (EDTA) (SSPE) buffer were purchased from Sigma (St Louis, MO, USA). Cholera toxin (CT) was from Calbiochem (La Jolla, CA, USA). Sp and Rp-cyclic 3',5'-hydrogen phosphorothioate adenosine triethylammonium salt ( $\mathrm{Sp}$ - and Rp-AMP) were from RBI (Natick, MA, USA). Purified IgE antibodies used as standards were obtained from Stallergenes (Fresnes, France). Purified mouse antihuman IgE monoclonal antibodies (moAbs) and antiCD40 moAbs were from Pharmingen (San Diego, CA, USA). Tween 20 was obtained from Merck (Darmstadt, GFR). Anti-CD20 moAbs were from Becton Dickinson (San Jose, CA, USA).

\section{Isolation of peripheral blood mononuclear cells}

Human PBMC were isolated from healthy nonatopic donors by density gradient centrifugation on Ficoll (Eurobio, Les Ulis, France). The cells recovered at the interface were washed twice by centrifugation at 1,800 rpm in RPMI 1640, and were resuspended in a culture medium consisting of RPMI 1640 supplemented with $10 \%$ FCS, $2 \mathrm{mM}$ glutamine, $50 \mathrm{U} \cdot \mathrm{mL}^{-1}$ penicillin and 50 $\mathrm{mg} \cdot \mathrm{mL}^{-1}$ streptomycin (RMPI-FCS) at a final concentration of $2 \times 10^{6}$ cells $\cdot \mathrm{mL}^{-1}$.

\section{B-lymphocyte preparation}

Normal B-lymphocytes were purified from PBMC according to the experimental procedure described by MiLtenyi et al. [13]. PBMC resuspended in PBS solution containing $1 \%$ BSA plus $0.01 \%$ sodium azide plus $5 \mathrm{mM}$ EDTA, were incubated with paramagnetic beads ( $200 \mathrm{~mL}$ of the solution provided by the manufacturers for $10^{8}$ cells) conjugated to anti-CD19 moAbs. Cells were next deposited on specially designed columns and separated into positive and negative populations using a high magnetic field (Miltenyi Biotec, Sunnyvale, CA, USA). Unlabelled CD19- cells were eluted from the column, whilst CD19+ B-cells were recovered by vigorous washing of the column matrix after its removal from the magnet. After staining purified B-cell preparations with fluorescein isothiocyanate (FITC)-conjugated specific anti-CD20 moAbs (Becton Dickinson, Moutain View, CA, USA), fluorescence analysis was performed with a FACSstar+ (Becton Dickinson, Sunnyvale, CA, USA) and showed that they contained $>98 \%$ B-lymphocytes. B-lymphocytes were then resuspended in RPMI-FCS at a final concentration of $1 \times 10^{6}$ cells $\cdot \mathrm{mL}^{-1}$ and were assessed for viability by trypan blue exclusion after 13 days of culture.

\section{Measurement of IgE production}

PBMC or purified B-lymphocytes were cultured for 13 days, after which supernatants were harvested and tested for their IgE concentrations. Briefly, 96-well enzyme-linked immunosorbent assay (ELISA) plates (Maxisorp, Nunc) were coated overnight at $4^{\circ} \mathrm{C}$ with 100 $\mu \mathrm{L} \cdot$ well $^{-1}\left(10 \mu \mathrm{g} \cdot \mathrm{mL}^{-1}\right)$ of anti-IgE moAb in $0.1 \mathrm{M}$ $\mathrm{NaHCO}_{3}$ buffer, pH 9.6. After five washes with PBS added with $0.05 \%$ Tween 20 (PBS-Tween), the plates were incubated for $1 \mathrm{~h}$ at $37^{\circ} \mathrm{C}$ with RPMI-FCS to saturate nonspecific protein-binding sites. One hundred microlitres per well of culture supernatants or defined solutions of $\operatorname{IgE}$ standards was then added and the plates were incubated for $2 \mathrm{~h}$ at $37^{\circ} \mathrm{C}$. After washing the plates five times with PBS-Tween, $100 \mu \mathrm{L}$ of $1 / 10,000$ diluted peroxidase-labelled anti-IgE moAb was added to each well, and incubation was continued for $2 \mathrm{~h}$ at $37^{\circ} \mathrm{C}$. After five washes with PBS-Tween, $100 \mu \mathrm{L}$ of OPD $(0.5$ $\mathrm{mg} \cdot \mathrm{mL}^{-1}$ ) in $0.1 \mathrm{M}$ citric acid and $0.1 \mathrm{M} \mathrm{Na}_{2} \mathrm{HPO}_{4}$ buffer was added. The reaction was stopped with $100 \mu \mathrm{L}$ of $\mathrm{H}_{2} \mathrm{SO}_{4}$, and absorbance was assessed at $492 \mathrm{~nm}$ with an ELISA reader (Dynatech, Alexandria, VA, USA). The sensitivity of the assay was $300 \mathrm{pg} \cdot \mathrm{mL}^{-1}$. No cross-reactivity has been observed with others subclasses of antibodies.

\section{Ribonucleic acid (RNA) isolation and Northern Blot assays}

Total RNA was isolated from PBMC using the method described by CHOMCZYNSKI and SACCHI [14]. Aliquots of RNA $(20 \mu \mathrm{g})$ were electrophoresed in $1 \%$ agarose, $6 \%$ formaldehyde gels, electrotransferred to Hybond $\mathrm{N}^{+}$membranes (Pharmacia, St-Quentin en Yvelines, France), and fixed by UV irradiation. Prehybridization and hybridization were performed at $68^{\circ} \mathrm{C}$ in a solution containing $0.5 \%$ sodium dodecyl sulphate (SDS), Denhardt $5 \times$, SSPE $5 \times$, dextran sulphate $5 \times$, salmon sperm $20 \mu \mathrm{g} \cdot \mathrm{mL}^{-1}$ and formamide $50 \%$. Hybridization was performed overnight in a fresh solution containing a ${ }^{32} \mathrm{P}$-labelled RNA probe specific for the constant regions of the $\varepsilon$ chain of $\operatorname{IgE}$ (CE) $\left(1 \times 10^{6} \mathrm{cpm} \cdot \mathrm{mL}^{-1}\right)$. The membranes were washed for $30 \mathrm{~min}$ at room temperature in $1 \times$ standard sodium citrate $(\mathrm{SSC}) / 0.1 \% \mathrm{SDS}$, and twice in $0.1 \times \mathrm{SSC} / 0.1 \%$ $\mathrm{SDS}$ at $68^{\circ} \mathrm{C}$. They were then autoradiographed for 5 days at $-80^{\circ} \mathrm{C}$ on RPN Hyperfilm (Amersham) using two intensifying screens.

\section{RNA probe}

In order to detect the IgE mRNA, a probe complementary to its sequence was constructed. A complementary deoxyribonucleic acid (cDNA) corresponding to a part of the $\mathrm{CH} 2-\mathrm{CH} 4$ domain of the $\mathrm{C} \varepsilon$ molecule was obtained by reverse transcription-polymerase chain reaction (RT-PCR) experiments using oligonucleotides corresponding to nucleotides 228-244 and 830-846 of the published sequence [15]. These oligonucleotides were flanked by EcoR1 and BamH1 sites to facilitate further cloning. One milligram of total RNA from the U266B1 cell line (kindly provided by G. Delespesse, University of Montreal, Montreal, Canada) was reverse transcribed 
using a commercial kit (Promega, Madison, WI, USA) for $15 \mathrm{~min}$ at $42^{\circ} \mathrm{C}$. cDNA $(5 \mathrm{~mL})$ was then amplified by 35 cycles of PCR at an annealing temperature of $65^{\circ} \mathrm{C}$. The PCR products were electrophoresed in Tris-borate/ EDTA buffer and an expected band of 490 base pairs (bp) was excised from the gel, purified out of agarose (Plasmid Midi kit, Qiagen, Chatsworth, CA, USA) and digested with EcoR1 and BamH1 (Stratagene, La Jolla, CA, USA). This DNA was ligated overnight at $15^{\circ} \mathrm{C}$ with pBluescript II KS (-) (Stratagene) treated with calf intestine alkaline phosphatase. The XL1 Blue bacteria (Stratagene) were then transformed with the ligation mixture. The white colonies obtained after blue/white selection were analysed for the presence of a $490 \mathrm{bp}$ insert. One "positive" clone was selected and partially sequenced to confirm the presence of the insert using a commercial sequencing kit (Applied Biosystem, Foster, CA, USA). The plasmid containing the insert was then used for in vitro transcription of a ${ }^{32} \mathrm{P}$-labelled riboprobe using a commercial kit (Stratagene).

\section{Determination of intracellular cAMP}

A commercial radioimmunoassay (RIA) cAMP-test was used (NEN, Dreieich, Germany). PBMC $\left(2 \times 10^{6}\right.$ cells $\cdot \mathrm{mL}^{-1}$ ) were incubated in RPMI-FCS for 5 min with the indicated stimuli, then harvested, washed in cold PBS and incubated for $20 \mathrm{~min}$ in $0.1 \mathrm{M} \mathrm{HCl}$ at $4^{\circ} \mathrm{C}$ [16].

\section{Statistical analysis}

Results are expressed as mean \pm SEM of at least three experiments and were compared using the nonparametric Mann-Whitney statistical test.

\section{Results}

Effect of IL-4 and fenoterol on IgE production and on IgE mRNA expression

In earlier studies, we demonstrated that the $\beta_{2}$-adrenoceptor agonist, salbutamol potentiates the effect of IL-4 on IgE production by human PBMC. This effect was confirmed in this study by the experiments using fenoterol and presented in figure 1. Fenoterol, which is ineffective in inducing $\operatorname{IgE}$ production when added alone to the cell cultures $\left(<0.3 \mathrm{ng} \cdot \mathrm{mL}^{-1}\right)$, enhanced the IgE production induced by IL-4 in a dose-dependent manner, with a peak effect observed at $1 \mu \mathrm{M}$.

To further investigate the mechanism underlying this effect, Northern Blot experiments were conducted to assess the effects of these drugs on IgE mRNA expression. Results showed that IL-4 $\left(30 \mathrm{U} \cdot \mathrm{mL}^{-1}\right)$ induced the appearance of a $2.2 \mathrm{~kb}$ productive IgE mRNA after 10 days of culture (fig. 2). When the cells were stimulated with IL-4 in the presence of fenoterol $(1 \mu \mathrm{M})$, results showed that this drug potentiated the effect of IL-4 at the IgE mRNA level. Densitometric analysis of three

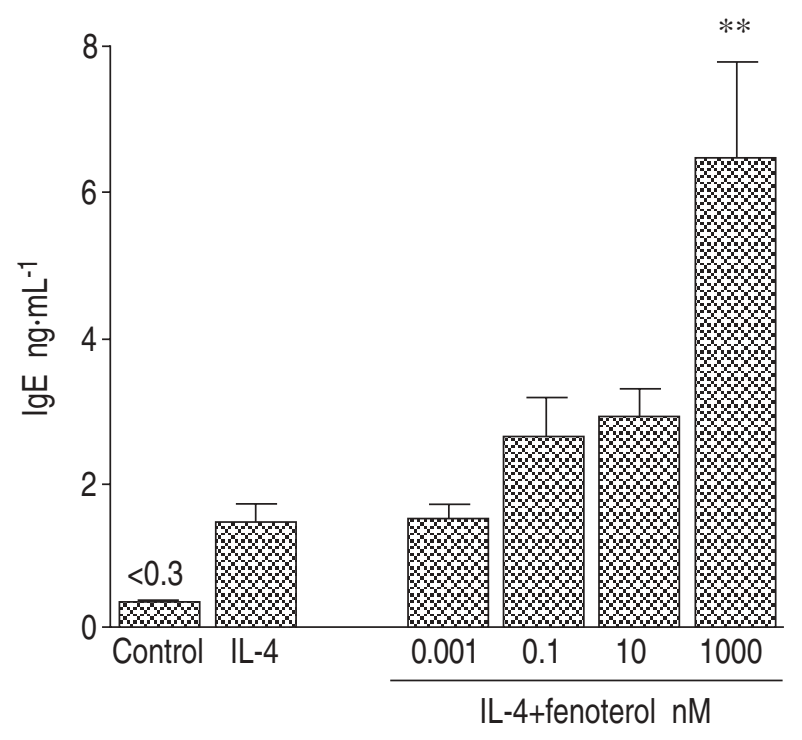

Fig. 1. - Effect of fenoterol on the IL-4-induced IgE production by human PBMC. PBMC $\left(2 \times 10^{6}\right.$ cells $\left.\cdot \mathrm{mL}^{-1}\right)$ obtained from healthy donors were added with IL-4 (30 U.mL-1) and cultured for 13 days in the presence or absence of fenoterol (0.001-1000 nM). Cell-free supernatants were harvested and stored frozen prior to $\operatorname{IgE}$ determinations by ELISA (mean \pm SEM of three experiments). **: $\mathrm{p}<0.01$, compared to IL-4-stimulated cells. IL-4: interleukin-4; IgE: immunoglobulin E; PBMC: peripheral blood mononuclear cells; ELISA: enzymelinked immunosorbent assay.

\section{IL-4}

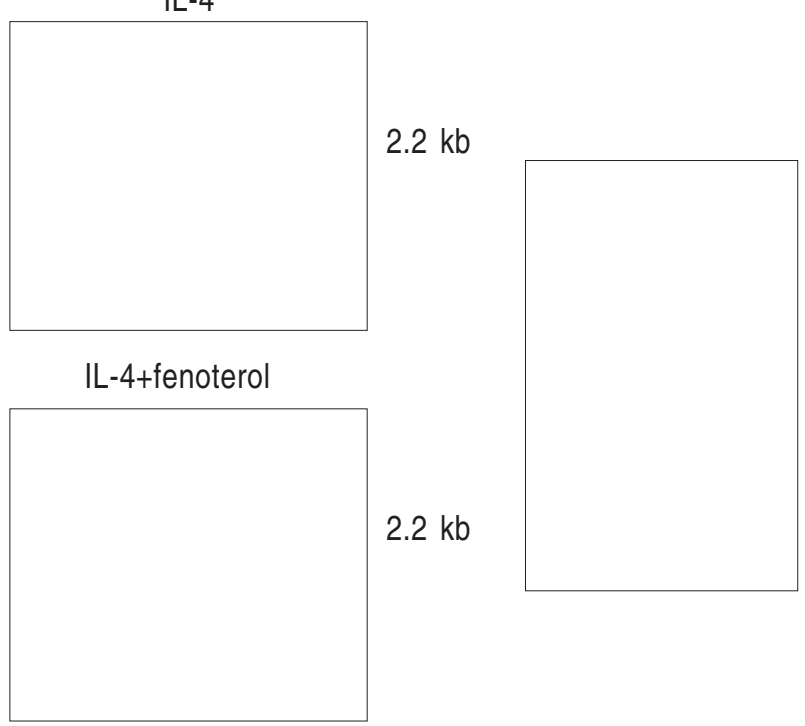

Fig. 2. - Fenoterol potentiated the expression of the IL4-induced IgE mRNA. PBMC were stimulated for 10 days with IL-4 $\left(30 \mathrm{U} \cdot \mathrm{mL}^{-1}\right)$ alone or with IL-4 and fenoterol $(1 \mu \mathrm{M})$ together (IF). Total cellular RNA was isolated, size fractionated $\left(20 \mu \mathrm{g} \cdot \mathrm{lane}^{-1}\right)$ and blotted onto a nylon membrane. The membranes were hybridized with a ${ }^{32} \mathrm{P}-$ labelled RNA probe specific for IgE. The ethidium bromide staining pattern of the membrane from which the Northern Blot was made shows equivalence of RNA loading because IL-4 was found to significantly inhibit the expression of $\beta$-actin mRNA IF means RNA obtained from cells stimulated with IL-4 and fenoterol $(1 \mu \mathrm{M})$. $28 \mathrm{~S}$ and $18 \mathrm{~S}$ are constant of sedimentation of ribosomal RNA. RNA: ribonucleic acid; mRNA: messenger RNA. For further abbreviations see legend to figure 1 .

different experiments indicated that fenoterol induced a marked increase in the mRNA expression compared to the effect of IL-4 added alone to the cell cultures (data not shown). 


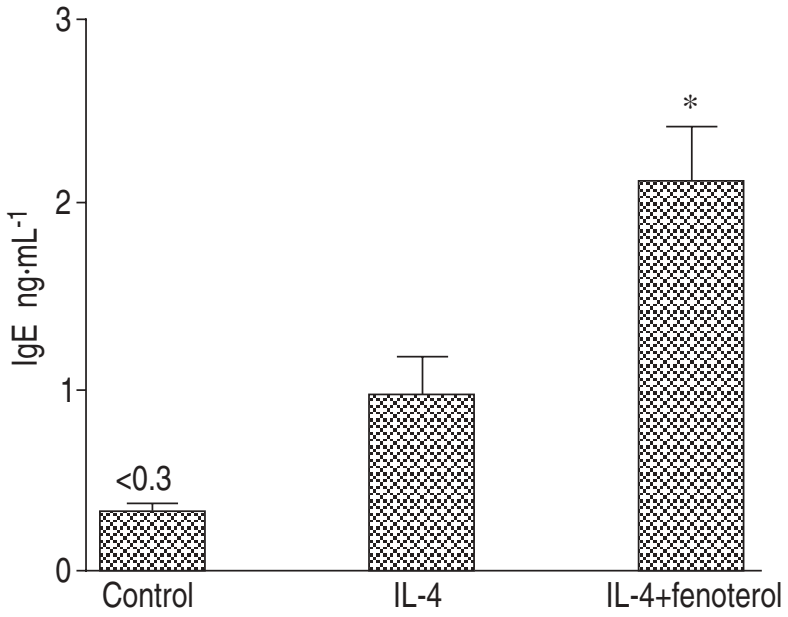

Fig. 3. - Fenoterol enhanced the IL-4-induced IgE production by purified B-cells. Purified B-lymphocytes $\left(1 \times 10^{6}\right.$ cells $\left.\cdot \mathrm{mL}^{-1}\right)$ were cultured with anti-CD40 MoAbs $\left(1 \mathrm{mg} \cdot \mathrm{mL}^{-1}\right)$ and IL-4 $\left(30 \mathrm{U} \cdot \mathrm{mL}^{-1}\right)$ alone or with IL-4 and fenoterol $(1 \mu \mathrm{M})$ together. Supernatants were harvested after 13 days of culture and $\mathrm{IgE}$ concentrations were measured by specific ELISA. Results are expressed as mean \pm SEM of three different experiments. *: p<0.05 compared to IL-4-stimulated cells. For abbreviations see legend to figure 1 .

\section{Effect of fenoterol on purified B-lymphocytes}

We also studied the effect of fenoterol on purified Blymphocytes activated through their CD40 antigen. Fenoterol potentiated IgE production by purified B-cells stimulated with a combination of IL-4 and anti-CD40 MoAbs, but to a lesser extent as compared to the effect observed on PBMC. Compared to the effect of IL-4 added alone to the cell cultures, a two- to threefold significant increase $(\mathrm{p}<0.05)$ was observed (fig. 3). Additionally, results presented in table 1 indicate that fenoterol $(1 \mu \mathrm{M})$ increased the number of viable B-lymphocytes recovered when B-cells were simulated by anti-CD40 in the presence of IL-4.

\section{Effect of fenoterol on cAMP levels}

We investigated whether the effect of fenoterol on PBMC was associated with increases in intracellular cAMP levels. No effect on cAMP production was observed when the cells were stimulated with IL-4 for 5 min (30

Table 1. - Effect of fenoterol on the recovery of viable B-lymphocytes activated by anti-CD40 antibodies and IL-4

\begin{tabular}{lc}
\hline & $\begin{array}{c}\text { Viable cells } \\
\times 10^{5}\end{array}$ \\
\hline Control & $2.5 \pm 0.5$ \\
IL-4 & $3.5 \pm 1.2$ \\
IL-4+fenoterol & $4.8 \pm 2.3$ \\
\hline
\end{tabular}

B-lymphocytes were seeded at $1 \times 10^{6}$ cells $\cdot$ well $^{-1}$ in the presence of anti-CD40 MoAbs and with or without IL-4 (100 U.mL $\left.\mathrm{mL}^{-1}\right)$. Cultures were performed in the presence or absence of $1 \mu \mathrm{M}$ fenoterol. After 13 days of culture, viable B-lymphocytes were enumerated using the trypan blue dye exclusion method (mean \pm SEM of three experiments). MoAb: monoclonal antibody; IL-4: interleukin-4.
Table 2. - Effect of IL-4 and fenoterol on CAMP production (pmoles.10-6 cells) by PBMC

\begin{tabular}{lrc}
\hline & None & IL-4 $\left(30 \mathrm{U} \cdot \mathrm{mL}^{-1}\right)$ \\
\hline Control & $103 \pm 10$ & $103 \pm 24$ \\
Fenoterol $(1 \mu \mathrm{M})$ & $52 \pm 12$ & $413 \pm 48^{* *}$ \\
\hline
\end{tabular}

Cells $\left(2 \times 10^{6}\right.$ cells $\left.\cdot \mathrm{mL}^{-1}\right)$ were stimulated for 5 min with IL-4 $\left(30 \mathrm{U} \cdot \mathrm{mL}^{-1}\right)$ or fenoterol $(1 \mu \mathrm{M})$ alone or with a combination of IL-4 and fenoterol. cAMP concentrations were then measured as described in the Materials and Methods section. Results are expressed as mean \pm SEM of four different experiment. **: p<0.01 compared to IL-4-stimulated cells. cAMP: cyclic adenosine monophosphate; PBMC: peripheral blood mononuclear cells; IL-4: interleukin-4.

$\left.\mathrm{U} \cdot \mathrm{mL}^{-1}\right)$. Fenoterol induced a nonsignificant decrease of cAMP production as compared to nonstimulated control cells (table 2). By contrast, when the cells were stimulated with IL-4 and fenoterol together $(1 \mu \mathrm{M})$, a significant increase $(\mathrm{p}<0.01)$ in cAMP production was noted (table 2) as compared to IL-4-stimulated cells.

Effect of cell permeable cAMP analogues on IgE production by PBMC

Because many of the effects of $\beta_{2}$-adrenoceptor agonists are thought to be mediated through increases in intracellular cAMP levels, the effect of db-cAMP $(100 \mu \mathrm{M})$ and Sp-AMP $(10 \mu \mathrm{M})$ were then examined in separate experiments. As shown in figure 4, both drugs $(100 \mu \mathrm{M})$ significantly potentiated the effect of IL-4 on IgE production $(\mathrm{p}<0.05)$. The increases were $3-4$ times higher with these compounds than with IL-4 alone.

Role of PKA in the modulation of IgE production by fenoterol

To determine whether the increase in IgE production is mediated through cAMP-dependent phosphorylation,

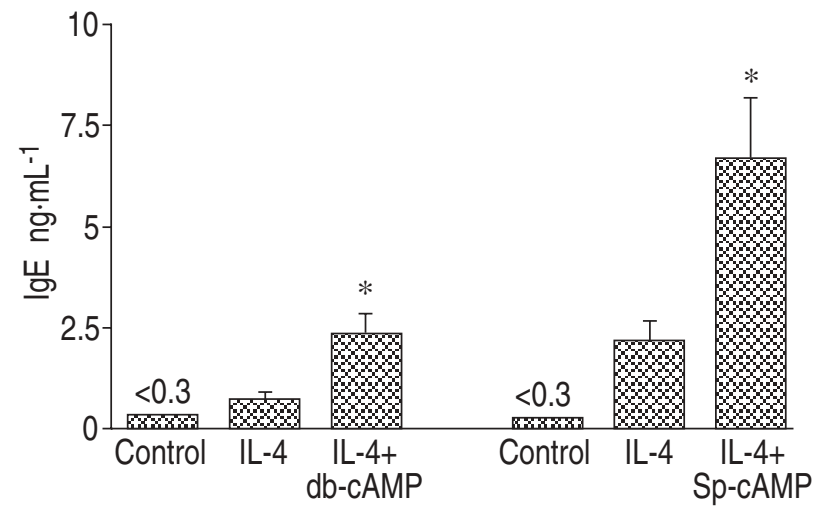

Fig. 4. - Effect of cell permeable cAMP analogues on IgE production by PBMC. PBMC were cultured with IL-4 $\left(30 \mathrm{U} \cdot \mathrm{mL}^{-1}\right)$ alone or IL-4 plus db-cAMP $(100 \mu \mathrm{M})$ or IL-4 plus Sp-AMP $(10 \mu \mathrm{M})$. Supernatants were harvested after 13 days of culture and $\operatorname{IgE}$ concentrations were measured by specific ELISA. Results are expressed as mean \pm SEM of three different experiments. *: p<0.05 compared to IL-4-stimulated cells. cAMP: cyclic adenosine monophosphate; db-cAMP: dibutyrylcAMP. For further abbreviations see legend to figure 1 . 


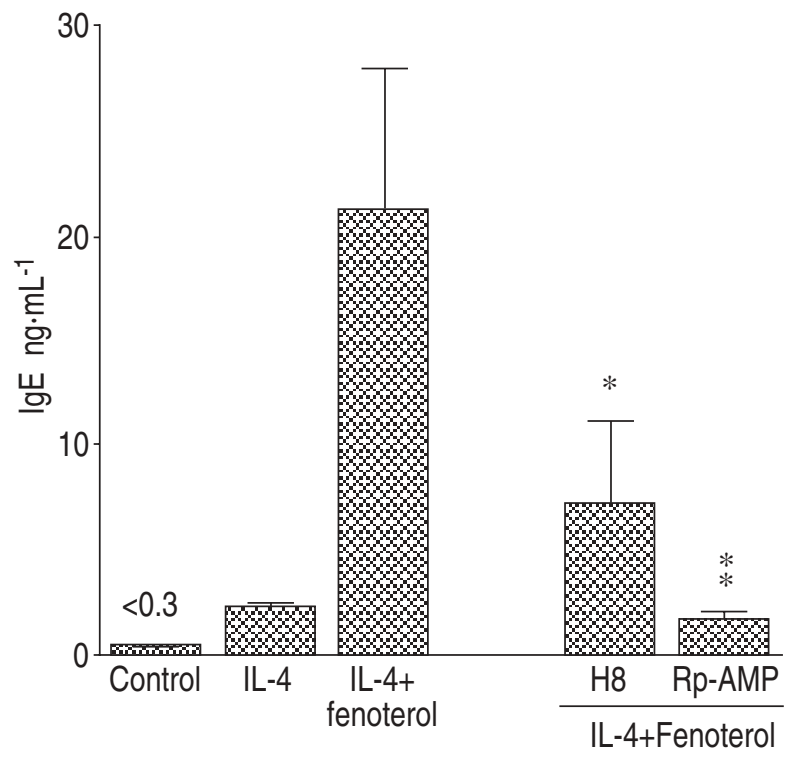

Fig. 5. - The potentiating effect of fenoterol on IgE production was partially reversed in the presence of PKA inhibitors. PBMC were preincubated for $30 \mathrm{~min}$ with $\mathrm{H} 8(10 \mu \mathrm{M})$ or Rp-AMP $(10 \mu \mathrm{M})$. IL-4 $\left(30 \mathrm{U} \cdot \mathrm{mL}^{-1}\right)$ and fenoterol $(1 \mu \mathrm{M})$ were then added alone or in combination and the cells were cultured for 13 days. Results are expressed as mean \pm SEM of three different experiments. *: $\mathrm{p}<0.05 ; * *: \mathrm{p}<0.01$, compared to the results obtained in the presence of IL-4 and fenoterol. H8: N-5-isoquinolinesulphonamide. For further abbreviations see legend to figure 1 .

inhibitors of PKA were used. H8 and Rp-AMP both compete for the adenosine triphosphate (ATP)-binding site of the catalytic subunit but do not alter the binding of cAMP to the regulatory subunits of PKA. Cells were pretreated for 30 min with H8 $(10 \mu \mathrm{M})$ or Rp-AMP (10 $\mu \mathrm{M})$ and were then stimulated with either IL-4 alone or

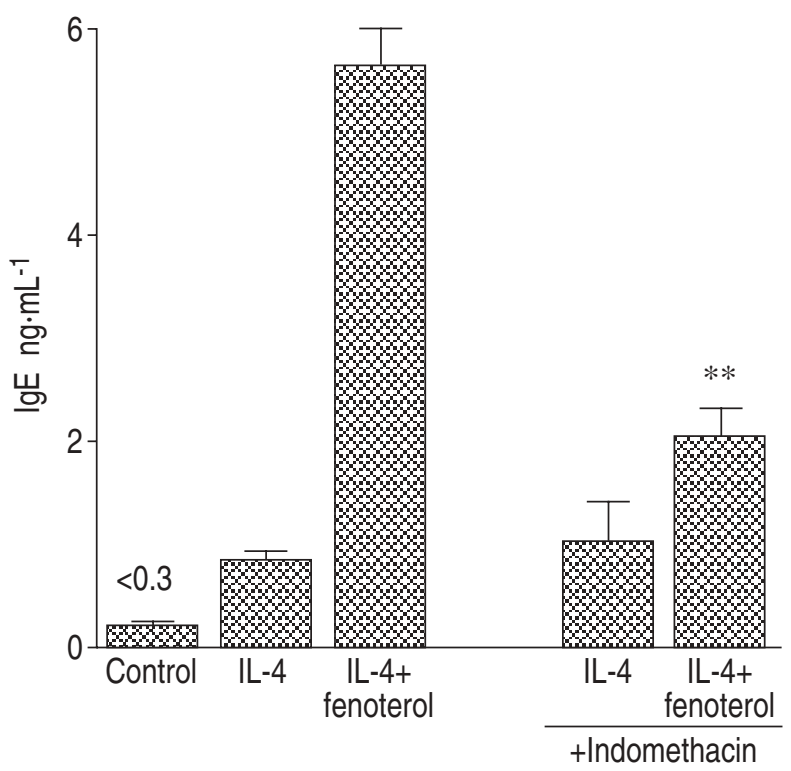

Fig. 6. - The potentiating effect of fenoterol on IgE production was partially reversed in the presence of indomethacin. PBMC were preincubated for $30 \mathrm{~min}$ with indomethacin $(10 \mu \mathrm{M})$ alone or a combination of IL-4 $\left(30 \mathrm{U} \cdot \mathrm{mL}^{-1}\right)$ and fenoterol $(1 \mu \mathrm{M})$. The cells were cultured for 13 days (results are expressed as mean \pm SEM of three different experiments. $* *: \mathrm{p}<0.01$, compared to the results obtained in the presence of IL-4 and fenoterol. For abbreviations see legend to figure 1. with IL-4 and fenoterol together. No effect of the inhibitors was observed on the IL-4-induced IgE production (data not shown). By contrast, the potentiating effect of fenoterol on $\mathrm{IgE}$ production was significantly inhibited by $\mathrm{H} 8$ $(\mathrm{p}<0.05)$ and Rp-AMP $(\mathrm{p}<0.01)$ (fig. 5).

\section{Inhibition of the effect of fenoterol on IgE production by indomethacin}

The effect of the other cAMP-elevating agents on IL4-driven IgE production suggests that $\beta_{2}$-adrenoceptor agonists may mediate their effect through endogeneous release of prostaglandin $\mathrm{E}_{2}\left(\mathrm{PGE}_{2}\right)$ by monocytes. To test this hypothesis, PBMC were preincubated with indomethacin $(10 \mu \mathrm{M})$ for $30 \mathrm{~min}$ and then stimulated with IL-4 and fenoterol. No modification was observed on the IL-4-induced IgE production (fig. 6). By contrast, indomethacin significantly inhibited $(p<0.01)$ the potentiating effect of fenoterol on IgE production.

\section{Discussion}

The results presented in this study indicate that fenoterol and other cAMP analogues potentiate IL-4-induced IgE production by human PBMC. These results were confirmed by the use of another $\beta_{2}$-adrenoceptor agonist, salbutamol (data not shown). To a lesser extent, the same effect was observed on purified B-lymphocytes. The enhanced IgE production by PBMC seems to be mediated through an increase of the productive IgE mRNA expression. The transduction pathway for this potentiating effect depends on PKA activation, since it is blocked by inhibitors of this kinase. Moreover, the same effect was observed when a direct activator of PKA was used. Finally, the potentiating effect of $\beta_{2}$-adrenoceptor agonists is inhibited in the presence of indomethacin, suggesting that their activities might be mediated through a prostaglandin release.

The effect of $\beta_{2}$-adrenoceptor agonists on human IgE production seems to be related to cAMP pathway, since these drugs induce an increase in intracellular cAMP levels. In the present study, this was observed only in the presence of IL-4. Moreover, the cell permeable product db-cAMP, also potentiated the effect of IL-4 on IgE production. Thus, the potentiating effect of $\beta_{2}$ adrenoceptor agonists might be explained by an interaction of cAMP at an unknown stage of IL-4 signalling. This notion finds support in a recent study suggesting a cross-talk between the IL-4 signalling pathway and PKA activation during human B-cell proliferation [17]. Thus, the IL-4 and $\beta_{2}$-adrenergic signalling pathways may overlap one another after the activation of the kinase. This notion is supported in recent studies showing that IL-1 and cAMP induce immunoglobulin (Ig) light chain transcription by activating the nuclear factor $-\kappa \mathrm{B}(\mathrm{NF}-\kappa \mathrm{B})$ protein [18].

Although previous studies have suggested a direct effect of cAMP on B-cell differentiation, we have no evidence which cells among B-cells, T-cells and monocytes are 
implicated in the modulation of IgE production by cAMP. Fenoterol potentiates the IL-4-induced IgE production by purified B-lymphocytes, but this effect seems to be related to enhanced cell viability. Furthermore, the potentiating effect on IgE production is less pronounced on purified B-cells than on PBMC. Thus, the modulation of IgE production by $\beta_{2}$-adrenoceptor agonists is likely to be mediated through another cell type, most likely Tlymphocytes or monocytes. We have previously shown that the enhanced IgE production might be explained by the inhibition of interferon- $\gamma($ IFN- $\gamma$ ) production by PBMC [11]. The results presented in this study also suggest that the effect of $\beta_{2}$-adrenoceptor agonists might be explained by an enhanced release of $\mathrm{PGE}_{2}$. This also suggests that the effect of fenoterol could be explained by the activation of monocytes. Thus, further experiments are required to indicate whether or not the effect of fenoterol could be explained by the release of prostaglandins. Interestingly, it has been reported that $\mathrm{PGE}_{2}$ potentiates the IL-4-induced $\mathrm{IgE}$ production by murine B-lymphocytes [19].

Since the concentrations used in this study are physiologically relevant, the present results suggest that exposure to $\beta_{2}$-adrenoceptor agonists may profoundly influence $\mathrm{IgE}$ antibody production. In the presence of IL-4, this effect is associated with an increased intracellular cAMP level followed by an activation of PKA. Moreover, the present results suggest that the increased IgE production might be mediated by the activation of the cyclo-oxygenase pathway. Given the clinical importance of these drugs in the treatment of asthma, further studies are now underway to determine whether $\beta_{2}$-adrenoceptor agonists exhibit the same effects in asthmatic patients.

Acknowledgements: The authors thank G. Bouër for assistance in preparing this manuscript

\section{References}

1. Barnes PJ. A new approach to the treatment of asthma. $N$ Engl J Med 1989; 321: 1517-1527.

2. Church MK, Hiroi J. Inhibition of IgE-dependent histamine release from human dispersed lung mast cells by anti-allergic drugs and salbutamol. Br J Pharmacol 1987; 90: 421-429.

3. Pearce N, Grainger J, Atkinson M, et al. Case-control study of prescribed fenoterol and death from asthma. Thorax 1990; 45: 170-175.

4. Sears MR, Taylor DR, Print CG, et al. Regular inhaled beta-agonist treatment in bronchial asthma. Lancet 1990; 336: 1391-1396.

5. Spitzer WO, Suissa S, Ernst P, et al. The use of $\beta$ agonist and the risk of death and near death from asthma. N Engl J Med 1992; 326 (8): 501-506.

6. Dailey MO, Schreurs J, Shulman H. Hormone receptors on cloned T-lymphocytes. J Immunol 1988; 140: 29312936.

7. Sanders VM, Powell-Oliver FE. $\beta_{2}$-adrenoceptor stimulation increases the number of antigen-specific precursor B-lymphocytes that differentiate into IgM-secreting cells without affecting burst size. J Immunol 1992; 148: 1822-1828.

8. Fonteh AN, Winkler JD, Torphy TJ, Heravi J, Undem BJ, Chilton FH. Influence of isoproterenol and phosphodiesterase inhibitors on platelet-activating factor biosynthesis in the human neutrophils. J Immunol 1993; 151: 339-350.

9. Lefkowitz RJ, Caron MG. Adrenergic receptors: models for the study of receptors coupled to guanine nucleotide regulatory proteins. J Biol Chem 1988; 263: 4993-4996.

10. Roesler WJ, Vandenbark GR, Hanson RW. Cyclic AMP and the induction of eucaryotic gene transcription. $J$ Biol Chem 1988; 263: 9063-9066.

11. Coqueret O, Dugas B, Mencia-Huerta JM, Braquet P. Regulation of IgE release from human mononuclear cells by $\beta_{2}$-adrenoceptor. Clin Exp Allergy 1995; 25: 304-311.

12. Coqueret $\mathrm{O}$, Petit-Frere $\mathrm{C}$, Lagente V, Moumen $\mathrm{M}$, Mencia-Huerta JM, Braquet P. Regulation of IgE release by $\beta_{2}$-adrenoceptor agonists in vivo and in vitro in the mouse. Int Arch Allergy Appl Immunol 1994; 105: 171-176.

13. Miltenyi S, Müller W, Weichel W, Radbruch A. High gradient magnetic cell separation with MACS. Cytometry 1990; 11: 231-238.

14. Chomczynski P, Sacchi N. Single-step method of RNA isolation by acid guanidium thiocyanate-phenol-chloroform extraction. Anal Biochem 1987; 162: 156-159.

15. Max EE, Battey J, Ney R, Kirsh IR, Leder P. Duplication and deletion in the human immunoglobulin $\mathrm{E}$ gene. Cell 1982; 29: 691-699.

16. Chabrier PE, Roubert P, Longchampt MO, Plas P, Braquet P. Regulation of atrial natruretic factor receptors by angiotensin II in rat vascular smooth muscle cells. J Biol Chem 1988; 263: 13199-13202.

17. Vazquez A, Auffredou MT, Galanaud P, Leca G. Modulation of IL-2 and IL-4-dependent human B-cell proliferation by cyclic AMP. J Immunol 1991; 146: 4222-4227.

18. Chedid F, Mizel SB. Involvement of cyclic AMP-dependent protein kinases in the signal transduction pathway for interleukin-1. Mol Cell Biol 1990; 10: 3824-3827.

19. Roper RL, Conrad DH, Brown DM, Warner GL, Phipps RP. Prostaglandin $E_{2}$ promotes IL-4 induced IgE and $\mathrm{IgG}_{1}$ synthesis. J Immunol 1990; 145: 2644-2651. 